\title{
PoEsia, PSiCANÁlise E A CONSTRUÇÃO DO CONHECIMENTO: REVERBERAÇÕES
}

\author{
Eduardo Rodrigues Peyon
}

Esta dissertação de mestrado trata das relações entre poesia e psicanálise buscando compreender por que Freud tanto citou os poetas na construção do edifício teórico psicanalítico. Nesse sentido, traçou-se um percurso buscando discutir a noção de poesia, para depois atravessar alguns trabalhos de Freud onde não apenas a poesia está presente, como a própria teoria avança através de novos modelos aqui compreendidos como poéticos. Por fim, toma-se o pensamento de Jacques Derrida como ferramenta importante para apontar e refletir sobre as rupturas poéticas empreendidas pela psicanálise.

\section{BANCA:}

Ana Maria Rudge (Orientadora)

Betty Bernardo Fuks

Paulo Cesar Duque Estrada

Data de defesa: 22/02/2008 


\section{ENCONTROS, DESENCONTROS OU CONFRONTOS ENTRE GERAÇÕES? UM ESTUDO COM FAMÍLIAS COM ADOLESCENTES NA CONTEMPORANEIDADE}

Cristina Teixeira Marques Vieira da Silva

Este trabalho focaliza a percepção dos pais sobre a adolescência dos filhos e analisa as ressonâncias entre as gerações da família com adolescentes na contemporaneidade. Para isso, realizou-se um estudo de campo com sete casais da classe média urbana do Rio de Janeiro com filhos com idades entre 15 e 20 anos. Foram abordadas as seguintes temáticas: definição de adolescência; valores transmitidos geracionalmente; diálogo, liberdade e controle; tecnologia; consumo, violência e drogas; relações de gênero e sexualidade; a família do adolescente e as expectativas parentais.

\section{BANCA:}

Andrea Seixas Magalhães (Orientadora)

Edson Guimarães Saggese

Terezinha Féres-Carneiro

Data de defesa: 25/02/2008 


\section{A VELOZ OBSOLESCÊNCIA DOS APARELHOS CELULARES}

Priscilla da Silva Marx Andrade

Este estudo tem como foco principal investigar como os jovens da cidade do Rio de Janeiro estão lidando com a obsolescência e com as freqüentes inovações tecnológicas dos aparelhos celulares. Os depoimentos dos participantes revelaram que os celulares estão cada vez mais presentes na vida dos jovens. A maioria dos participantes, no entanto, troca de aparelho antes do tempo no qual considera que deveria trocar. As razões para esse movimento estão principalmente no fato de eles se sentirem fortemente atraídos pelas inovações tecnológicas dos celulares.

\section{BANCA:}

Ana Maria Nicolaci-da-Costa (Orientadora)

Denise Berruezo Portinari

Rosane de Albuquerque dos Santos Abreu

Data de defesa: 26/02/2008 


\title{
OBSERVANDO A CONEXÃO AFETIVA \\ EM CRIANÇAS AUTISTAS
}

\author{
Ana Maria Camelo Campos
}

A capacidade de conexão afetiva parece faltar às crianças com autismo, o que prejudica as experiências intersubjetivas primária e secundária e, conseqüentemente, o desenvolvimento simbólico. Esta pesquisa teve como objetivo investigar se e como ocorreu a conexão afetiva de 2 crianças TEA estando elas em interação com uma terapeuta. Foi incluído um grupo controle composto por 2 crianças DT. A descrição qualitativa revelou que é possível observar sinais sutis da conexão afetiva entre crianças autistas e a terapeuta.

\section{BANCA:}

Carolina Lampreia (Orientadora)

Denise Streit Morsch

Silvia Maria Abu-Jamra Zornig

Data de defesa: 27/02/2008 


\section{AMORES POSSÍVEIS: UM ESTUDO SOBRE A CONJUGalidade na Rocinha, Rio de JANEIRO}

Vanessa Maria de Sousa Maia

Este trabalho tem como objetivo analisar como se dão as relações amorosas em uma comunidade na cidade do Rio de Janeiro, a Rocinha. Partindo de uma análise do amor romântico e da contextualização da pobreza, encontramos diferentes tipos de arranjos conjugais, bem como balizadores diversos para as escolhas amorosas. Através de entrevistas semi-estruturadas, desvelamos as nuances da conjugalidade nessa população, suas singularidades e generalidades.

\section{BANCA:}

Junia de Vilhena (Orientadora)

Anna Paula Uziel

Maria Helena Rodrigues Navas Zamora

Data de defesa: 29/02/2008 


\title{
A PRESENÇA DA PSICANÁLISE NA obra DE Gilles Deleuze
}

\author{
Juliana Martins Rodrigues
}

A presente dissertação de mestrado procurou investigar a relação de Deleuze com a teoria psicanalítica. Buscou-se uma comparação entre o pensamento psicanalítico clássico, fundado numa lógica representacional, e o pensamento deleuziano, numa lógica imanente. Foi abordada ainda a contraposição deleuziana ao pensamento transcendente e sua proposta de criticá-lo a partir de um sistema aberto às singularidades e às multiplicidades. Por fim, foram formuladas algumas coordenadas para pensar uma psicanálise renovada, mais viva e mais criativa.

\section{BANCA:}

Carlos Augusto Peixoto Junior (Orientador)

Jorge Luiz Rocha de Vasconcellos

Regina Alice Neri

Data de defesa: 07/03/2008 


\section{ONDE ESTÁ VOCÊ AGORA ALÉM DE AQUI, DENTRO DE MIM? O LUTO DAS MÃES DE CRIANÇAS DESAPARECIDAS}

\section{Sandra Rodrigues de Oliveira}

O presente estudo teve como objetivo investigar o impacto do desaparecimento de um filho a partir da ótica das mães. Participaram da pesquisa 11 mulheres com filhos desaparecidos misteriosamente, no estado do Rio de Janeiro, entre os anos de 2002 e 2005. As crianças tinham entre 11 meses e 11 anos na ocasião do desaparecimento. Como metodologia, foram utilizadas entrevistas semiestruturadas e a técnica de análise de conteúdo. Constatou-se que, diante do desaparecimento de seus filhos, todas as participantes apresentaram reaçôes de negação, choque, desespero, medo, ansiedade, culpa, impotência, tristeza e raiva, em contraposição a sentimentos de esperança, fé, determinação e certeza do reencontro com o filho desaparecido. Além do impacto individual, mudanças importantes no relacionamento conjugal, com os outros filhos e demais membros da rede deflagram uma desestruturação global na vida destas mulheres.

\section{BANCA:}

Terezinha Féres-Carneiro (Orientadora)

Andrea Seixas Magalhães

Heliana de Barros Conde Rodrigues

Data de defesa: 14/03/2008 


\section{"SE ELE É ARTILHEIRO, EU TAMBÉM QUERO SAIR DO BANCO": UM ESTUDO SOBRE A CO-PARENTALIDADE HOMOSSEXUAL}

Alberto Carneiro B. de Souza

A presente pesquisa, valendo-se do aporte da teoria queer, teve como objetivo a investigação sobre a co-parentalidade homossexual masculina. Para tanto, foram entrevistados 3 casais do interior do estado do Rio de Janeiro, com idades variando de 19 a 31 anos, todos com filhos, oriundos de relação heterossexual anterior, com idades de 3 a 7 anos. A metodologia utilizada adotou a análise de discurso com entrevistas semi-estruturadas. Observou-se que todos os companheiros mostraram forte desejo de paternidade natural após a convivência com os companheiros que já eram pais. Também constatou-se grande preocupação destes companheiros com uma certa "moralização" da conduta e comportamento do par conjugal, bem mais acentuada do que nos próprios pais. A identidade homossexual cristalizada, muitas vezes, entrou em conflito com a co-parentalidade exercida, resultando em homofobia internalizada, processo que não parece ocorrer, de maneira geral, com os pais das crianças.

\section{BANCA:}

Terezinha Féres-Carneiro (Orientadora)

Anna Paula Uziel

Bernardo Jablonski

Data de defesa: 14/03/2008 


\section{DO MESMO À SURPRESA: UM PERCURSO PELO CONCEITO DE REPETIÇÃO EM FREUd E LACAN}

Tatiane Demaria Grova

A partir de três símiles freudianos, nosso percurso primeiramente intenta circunscrever a concepção de memória com a qual lida a psicanálise, noção que, segundo Jacques Lacan, sofre a incidência do registro simbólico desde seus primórdios. Em uma articulação ao que aí aparece como excedente, como o que não é encampado pelo significante, mas que surge como resto desta operação que o inscreve no aparelho psíquico, procuramos entrever o que se coloca como presença paradoxal que retorna e não se sujeita ao princípio do prazer. Para vislumbrar o que aí se articula, percorremos a conceituação freudiana de pulsão de morte, os comentários de Lacan acerca de das Ding, assim como a encarnação deste resto, o objeto $a$.

\section{BANCA:}

Marcus André Vieira (Orientador)

Lucia Grossi dos Santos

Maria Silvia Garcia Fernández Hanna

Data de defesa: 14/03/2008 


\section{O DINHEIRO DA MULHER E SUAS IMPLICAÇÕES NO CASAMENTO CONTEMPORÂNEO: UM ESTUDO \\ EXPLORATÓRIO}

Suzana Carvalho Maia Vasconcelos Rodrigues

A presente pesquisa trata do impacto do dinheiro recebido pela mulher na vida conjugal e de como a construção das regras nas decisóes financeiras são percebidas e questionadas por ela. Para tal, realizamos um estudo exploratório com 12 mulheres recém-casadas, trabalhando remuneradamente, sem filhos e pertencentes à classe média/alta carioca. Dentre os resultados obtidos, destacamos a autonomia e a individualidade da mulher conquistadas através do poder de decisão sobre o próprio dinheiro.

\section{BANCA:}

Bernardo Jablonski (Orientador)

Mirian Goldenberg

Terezinha Féres-Carneiro

Data de defesa: 18/03/2008 


\title{
O TRABALHO DO LUTO E A EXPERIÊNCIA ANALÍTICA: TRANSITORIEDADE E CONTINGÊNCIA
}

\author{
Sandra Maria Costa Viola
}

Trata-se, nesta dissertação, de abordar o trabalho do luto como uma via possível do encaminhamento de uma análise para o seu término. Este trabalho implica em disponibilizar o sujeito para a transitoriedade do objeto e a contingência do falo. Buscamos destacar como se processa esta tarefa e sobre qual objeto ela recai. Vimos como a solução melancólica estampa a dificuldade do sujeito frente a esse objeto. Para alcançar nosso ponto de chegada, contamos com a perspectiva freudiana e pedimos a contribuição de Lacan e o prisma de sua leitura sobre o tema.

\section{BANCA:}

Marcus André Vieira (Orientador)

Ana Lucia Lutterbach Holck

Ana Maria Rudge

Data de defesa: 24/03/2008 


\title{
A ARTE DE SER CIDADÃO: EXPERIÊNCIAS DE JOVENS EM PROJETOS SOCIAIS A PARTIR DO TEATRO
}

\author{
Jessé Guimarães da Silva
}

Este estudo tem por objetivo investigar alguns modos de ser protagonizados por jovens, a partir da arte teatral, em projetos sociais, e a sua repercussão sobre a constituição da noção de cidadania. Particularmente, o trabalho se apóia nas análises desenvolvidas a partir de observaçōes da montagem da peça Urucubaca, trabalho realizado por jovens integrantes da Trupe de Teatro do Grupo Cultural Afro Reggae (GCAR), cujas atividades são realizadas no Parque Proletário de Vigário Geral, bairro do Rio de Janeiro.

\section{BANCA:}

Solange Jobim e Souza (Orientadora)

Bernardo Jablonski

Victor Hugo Adler Pereira

Data de defesa: 25/03/2008 


\section{CRIANDO OS FILHOS SOZINHA: A PERSPECTIVA FEMININA DA FAMÍLIA MONOPARENTAL}

Maria Cecília Ribeiro Moncorvo

Nesta pesquisa, foram entrevistadas 9 mulheres separadas e/ou divorciadas, com filhos pequenos, de classe média, moradoras da cidade do Rio de Janeiro. Os relatos dessas participantes revelaram aspectos de suas vivências da condição monoparental. Concluímos que os relatos femininos mostraram uma vivência positiva da situação de monoparentalidade. Essas mulheres demonstraram que valorizam a boa relação com seus filhos e o bem-estar emocional familiar, assim como a realização pessoal, sem priorizar um vínculo conjugal.

\section{BANCA:}

Andrea Seixas Magalhães (Orientadora)

Adriana Ferreira Paes Ribas

Bernardo Jablonski

Data de defesa: 27/03/2008 


\title{
ESCONDERIJOS DO TEMPO: O TEMPO LÓGICO DE JACQUES LACAN E SUAS COORDENADAS COLETIVAS
}

\author{
Rodrigo Lyra Carvalho
}

\begin{abstract}
"Esconderijos do tempo" busca situar a intervenção da temporalidade nas relaçôes entre o sujeito e a coletividade. A partir do artigo "O tempo lógico e a asserção de certeza antecipada", de Jacques Lacan, e das retomadas do tema por ele empreendidas ao longo de seu ensino, investigam-se as possibilidades de o sujeito se servir de suas alteridades internas para inscrever no coletivo as marcas de sua singularidade. Delineia-se um tal empreendimento a partir de um ato paradoxal, a "asserção subjetiva antecipatória", marcada pela introdução dos três tempos lógicos: o instante de ver, o tempo para compreender e o momento de concluir. Através deles, concebe-se o estabelecimento de uma lógica coletiva específica, resultado da transformação do afeto da angústia em um modo singular de estabelecer o laço social.
\end{abstract}

\section{BANCA:}

Marcus André Vieira (Orientador)

Ângela Cavalcanti Bernardes

Paulo Eduardo Viana Vidal

Data de defesa: 28/03/2008 


\section{O NOVO (VELHO) HOMEM: UM ESTUDO PSICOSSO- CIAL SOBRE A IMAGEM MASCULINA EM LIVROS DE AUTO- \\ AJUDA}

Sônia Suely de Almeida

Este estudo tem como foco principal investigar qual a imagem masculina, sob o aspecto da comunicação interpessoal, veiculada em livros de auto-ajuda para casais. Foram estudados os dois livros mais vendidos no Rio de Janeiro no período compreendido entre 2001 e 2005. As análises de discursos revelaram que o representante do sexo masculino apresenta-se com características comportamentais tanto associadas a épocas antigas quanto a condutas marcadamente contemporâneas - panorama que reflete o contexto do intitulado novo homem. Os livros de auto-ajuda reverberam uma imagem masculina já encontrada na sociedade, o que, provavelmente, levará o homem aos mesmos conflitos já vivenciados por ele na época atual.

\section{BANCA:}

Bernardo Jablonski (Orientador)

Leonel Azevedo de Aguiar

Maria Cristina Ferreira

Data de defesa: 31/03/2008 


\section{SilÊNCIO E RUÍDO: INTRODUÇÃO A UMA ABORDAGEM DA MÚSICA A PARTIR DE FREUD E LACAN}

Lourenço Astuá de Moraes

Embora a psicanálise tenha feito uso das mais diversas formas de arte, a música, comparativamente, foi deixada de lado. Partindo do silêncio, que elegemos como ponto de encontro entre música e psicanálise, passando pela pulsão tal como Freud a desenvolve e tal como Lacan a retoma, e chegando ao objeto $a$ lacaniano, concluímos que a música, forma de arte que é, se apresenta, por um lado, como aquilo que dá forma a um vazio, outro nome para o silêncio, e, por outro, como o que veicula, ainda que de forma velada, a voz do pai morto, uma das encarnações do objeto $a$ lacaniano.

\section{BANCA:}

Ana Maria Rudge (Orientadora)

Fernanda Theophilo da Costa-Moura

Vera Lucia Silva Lopes Besset

Data de defesa: 04/07/2008 